\title{
Up-regulation of human PNPase mRNA by $\beta$-interferon has no effect on protein level in melanoma cell lines
}

\author{
Kamil Gewartowski ${ }^{1,2}$, Rafal Tomecki ${ }^{1}$, Lukasz Muchowski ${ }^{1}$, Aleksandra \\ Dmochowska $^{1,2}$, Artur Dzwonek ${ }^{3}$, Michal Malecki ${ }^{1}$, Henryk Skurzak ${ }^{4}$, \\ Jerzy Ostrowski ${ }^{3}$ and Piotr P. Stepien ${ }^{1,2 \varpi}$ \\ ${ }^{1}$ Department of Genetics, Warsaw University; ${ }^{2}$ Institute of Biochemistry and Biophysics, Polish Academy of Sci- \\ ences, Warszawa, Poland; ${ }^{3}$ Department of Gastroenterology, and ${ }^{4}$ Department of Immunology, Medical Center \\ for Postgraduate Education, Maria Sklodowska-Curie Memorial Cancer Center and Institute of Oncology, \\ Warszawa, Poland; ${ }^{\otimes}$-mail: stepien@ibb.waw.pl
}

Received: 08 December, 2005; revised: 16 February, 2006; accepted: 16 February 2006 available on-line: 26 February, 2006

\begin{abstract}
Human mitochondrial polynucleotide phosphorylase (hPNPase) is an exoribonuclease localized in mitochondria. The exact physiological function of this enzyme is unknown. Recent studies have revealed the existence of a relationship between induction of hPNPase mRNA and both cellular senescence and growth arrest of melanoma cells following $\beta$-interferon treatment. The aim of this study was to verify whether the augmented hPNPase mRNA level results in increase of the protein level. In several cell lines established from five metastatic melanoma patients we did not find any such correlation. However, an elevated level of hPNPase protein was observed in interferon-induced HeLa and Jurkat cells. This increase was correlated with a slight shortening of poly(A) tails of mitochondrial ND3 transcript.
\end{abstract}

Keywords: PNPase, beta interferon, melanoma, poly(A) tails, human mitochondria, polynucleotide phosphorylase

Human polynucleotide phosphorylase (hPNPase) is a nuclear-encoded enzyme that localizes to mitochondria (Piwowarski et al., 2003). It displays 3'-5' exoribonuclease (Leszczyniecka et al., 2002) and poly(A) polymerase activities in vitro (Nagaike et al., 2005). Although the physiological function of the protein remains elusive to date, some reports indicate that it may participate in the regulation of mitochondrial RNA metabolism (Tomecki et al., 2004; Nagaike et al., 2005).

Human hPNPase (hPNPase old-35) was identified by the group of Paul Fisher in the screen for up-regulated transcripts in human melanoma cells that were induced to terminal differentiation by treatment with $\beta$-interferon and mezerein, and in primary human progeroid fibroblasts, which entered the state of cellular senescence. $\beta$-Interferon treatment of HO-1 melanoma cell line resulted in growth arrest and the induction of apoptosis (Leszczyniecka et al., 2002). The phenomenon of growth-arrest aris- ing from hPNPase up-regulation was further confirmed in HO-1 cells that overexpressed the protein from an adenoviral vector (Sarkar et al., 2003). The induction of hPNPase overexpression in human melanoma cells treated with $\beta$-interferon and the subsequent growth arrest were suggested to be significant for the conceivable gene therapy of melano$\mathrm{ma}$ and for the elucidation of the processes underlying inflammation and aging (Sarkar et al., 2004).

The mechanism linking the up-regulation of hPNPase with the cell growth inhibition is not clear yet. Of the two models proposed by Fisher's group, the first one assumes specific degradation of $c-m y c$ mRNA by the exoribonucleolytic activity of hPNPase (Sarkar et al., 2003), while the second one suggests that the overexpression of hPNPase may lead to the increased level of reactive oxygen species (ROS) and consequently to the growth arrest of melanoma cells (Sarkar et al., 2004). Interferon treatment has been also shown to correlate with the reduction of

Abbreviations: hPNPase, human polynucleotide phosphorylase; PBS, phosphate-buffered saline; TBE, tris-borate-EDTA buffer; wt, wild type. 
mitochondrial protein synthesis and the steady-state level of mitochondrial mRNA transcripts (Kortsaris et al., 1976; Shan et al., 1990; Matarrese et al., 2002). The mechanism of this phenomenon is not known but up-regulation of hPNPase could be responsible for lowering the mitochondrial transcript levels.

It is well known that melanoma cell lines vary in their response to $\beta$-interferon treatment (ChawlaSarkar et al., 2001; Leaman et al., 2002) and only a small percentage of patients with metastatic melanoma are sensitive to interferon therapy (Worm et al., 2001; Wysocki et al., 2002; Soengas \& Lowe, 2003). Thus, identifying those that are susceptible to $\beta$-interferon action might be significant for determining the optimal therapy.

The published data on the induction of hPNPase in melanoma cells by $\beta$-interferon were based on experiments conducted in a few established human melanoma cell lines only at the level of mRNA (Leszczyniecka et al., 2002). We decided to examine the induction of hPNPase in different melanoma cell lines obtained from metastatic tumors, to check whether the induction of hPNPase expression at the mRNA level results in the increased level of hPNPase protein itself and to correlate that with apoptosis. Such a correlation might prove to be useful in applying the hPNPase mRNA level as a marker of interferon susceptibility of human melanomas.

\section{METHODS}

Cell cultures and interferon treatment. Human melanoma cell lines established from Polish patients with metastatic melanoma were obtained from the collection available at the Cancer Centre - Institute of Oncology in Warsaw (Poland). HeLa, Jurkat, HEK 293 and five melanoma cell lines were from early passages: MeW151p21, MeW152p9, MeW155p11, MeW164p13, MeW165p10 and four from distant passages: MeW151p152, MeW152p158, MeW155p150, MeW164p161. Most of the melanoma cell lines were characterized for the presence of molecular tumour markers as tyrosinase, MUC-18, MAGE-3 and MART 1 (Kulik et al., 2001). Cells were grown at $37^{\circ} \mathrm{C}$ in $5 \% \mathrm{CO}_{2}$ humidified atmosphere in DMEM (Sigma) or Eagle's (Biomed) medium supplemented with 10\% fetal bovine serum (Gibco), $0.2 \mathrm{mM}$ glutamine and penicillin and streptomycin (Sigma). Cells were grown on plates as monolayers and after reaching $50 \%$ confluence they were treated with $1000 \mathrm{u} / \mathrm{ml}$ of $\beta$-interferon (PBL Biomedical Laboratories). Cells were harvested after 24 and $72 \mathrm{~h}$ of interferon treatment for RNA/protein purification and for apoptosis analyses, respectively.

Stable cell line. The cell line stably expressing hPNPase from its cDNA cloned into appropriate vector under the control of CMV promoter (HEKPNP) was made using The Flp-In ${ }^{\mathrm{TM}}$ System (Invitrogene) in the Flp-In ${ }^{\text {TM }}$ HEK 293 Host Cell Line according to the manufacturer's instructions. This cell line was grown in DMEM supplemented with $100 \mu \mathrm{g} / \mathrm{ml}$ hygromycin.

RNA isolation and cDNA synthesis. Total RNA was isolated using QIAshredder (Qiagen) and RNeasy mini kit (Qiagen) or TRI Reagent (Sigma). Following the use of TRI Reagent, RNA was treated with DNase I (Fermentas). Reverse transcription was performed with $2.5 \mu \mathrm{g}$ DNA-free RNA, oligo-(dT) ${ }_{18}$ primer and RevertAid ${ }^{\mathrm{TM}}$ M-MuLV Reverse Transcriptase (Fermentas). All steps were performed according to the manufacturer's instructions.

Semiquantitative RT-PCR. RT-PCR was carried out to assess the expression of hPNPase mRNA employing $\beta$-actin as an internal control. $5 \mu \mathrm{l}$ of the $10 \times$ diluted cDNA were added to $20 \mu \mathrm{l}$ of PCR reaction mixture containing buffer with $2.5 \mathrm{mM}$ $\mathrm{MgCl}_{2}, 0.5 \mathrm{mM}$ deoxynucleotide triphosphates, 1 unit of Taq DNA polymerase (Fermentas) and $1 \mu \mathrm{l}$ of Assays-on-Demand ${ }^{\mathrm{TM}}$ Gene Expression Assay Mix (Applied Biosystem catalog number for hPNPase: Hs00396733_g1 and for $\beta$-actin: Hs99999903_m1) as the primer pair. Preliminary experiments were performed in order to determine the exponential phase of the PCR amplification. PCR reaction proceeded as follows: denaturation at $95^{\circ} \mathrm{C}$ for $5 \mathrm{~min}$ and 29 cycles for hPNPase or 23 cycles for $\beta$-actin of $95^{\circ} \mathrm{C}$ $(15 \mathrm{~s}), 57^{\circ} \mathrm{C}(30 \mathrm{~s})$, and $72^{\circ} \mathrm{C}(15 \mathrm{~s})$. Products were separated in $2.5 \%$ agarose gels containing ethidium bromide and visualized with the use of Gene Genius Bio Imaging System (Syngen). The signal intensities of the PCR products were calculated by using GeneTools software (Syngen) and the standard curve was based on the co-amplification of various amounts of the given cDNA.

Real-time PCR. $5 \mu \mathrm{l}$ of the 10-fold diluted cDNA were used in the real-time PCR reaction, which was carried out using LightCycler (Roche) and QuantiTect SYBR Green PCR Kit (Qiagen). Primers for $\beta$-actin described in (Vandesompele et al., 2002) were applied for standardization. Primers PNP-RTFor (5'-CCATTACACCAGTATCTCTG-3') and PNPRT-Rev (5'-GGCAAGAGACTTCATTACTG-3') were used for the quantification of hPNPase mRNA levels relative to the $\beta$-actin and/or $\beta_{2}$ microglobulin standardization. PCR reaction proceeded as follows: $95^{\circ} \mathrm{C}$ (15 min) enzyme activation and 40 cycles of $95^{\circ} \mathrm{C}(15 \mathrm{~s}), 53^{\circ} \mathrm{C}\left(30 \mathrm{~s}\right.$, slope $\left.2^{\circ} \mathrm{C} / \mathrm{s}\right)$, and $72^{\circ} \mathrm{C}(15 \mathrm{~s})$, followed by the melting curve.

High resolution Northern analysis. High resolution Northern blots were prepared as described in (Tomecki et al., 2004). In brief, $5 \mu \mathrm{g}$ of total RNA in $50 \%$ formamide were run in 5\% denaturing acrylamide/urea gel in $1 \times$ TBE. RNA was blotted onto 
Nytran-N filter by electrotransfer in $0.5 \times$ TBE buffer using Trans-Blot Cell apparatus (Bio-Rad). Hybridizations were performed in PerfectHyb ${ }^{\mathrm{TM}}$ Plus buffer (Sigma). PCR product corresponding to the internal region of ND3 transcript was labeled with $\left[\alpha-{ }^{32} \mathrm{P}\right]-$ dATP using HexaLabel DNA Labeling Kit (Fermentas) and used as a probe. Filters were exposed to PhosphorImager screens (Sigma). Results were obtained by scanning the PhosphorImager screens using Storm Scanner (Molecular Dynamics), and analyzed using ImageQuant.

Western blot analysis. Total proteins were separated in the $8 \%$ SDS/polyacrylamide gel and electroblotted onto the Protran ${ }^{\circledR}$ nitrocellulose membrane (Bioscience) using TRANS-BLOT ${ }^{\circledR}$ (Bio-Rad). The filters were blocked for $3 \mathrm{~h}$ in $10 \%$ milk powder in PBS containing $0.1 \%$ Tween-20, and then incubated overnight with the rabbit polyclonal antibodies against hPNPase (described previously in Piwowarski et al., 2003), diluted 200 -fold in $10 \%$ milk powder in PBS with 1\% Tween-20. The filters were subsequently washed three times using PBS with $1 \%$ Tween-20. Afterwards, the membranes were incubated for $3 \mathrm{~h}$ with the mouse monoclonal anti-rabbit immunoglobulins-peroxidase conjugate (Sigma) diluted 2000-fold in 5\% milk powder in PBS with $0.1 \%$ Tween-20. The blots were washed three times in PBS with $0.1 \%$ Tween-20. Finally, horseradish peroxidase conjugates were visualized by enhanced chemiluminescence system (ECL: $50 \mu \mathrm{l}$ of $250 \mathrm{mM}$ luminol (Fluka), $25 \mu \mathrm{l}$ of $90 \mathrm{mM}$ coumaric acid (Sigma) and $3 \mu \mathrm{l}$ of $30 \% \mathrm{H}_{2} \mathrm{O}_{2}$ were dissolved in $10 \mathrm{ml}$ of $100 \mathrm{mM}$ Tris/ $\mathrm{Cl}, \mathrm{pH}=8.5$ ) and the exposure to $\mathrm{X}$ ray films (AGFA), which were then developed with the use of CURIX60 and scanned using SNAPSCAN system (AGFA). The resulting digital images were analyzed using ImageQuant v5.2 sofware. The protein loading was evaluated on the base of Ponceau $S$ Red staining of the membranes following semi-dry electrotransfer.

Analysis of apoptosis. Melanoma cells for apoptosis investigation were grown to $30-50 \%$ confluence and then treated with $\beta$-interferon $(1000 \mathrm{u} /$ $\mathrm{ml}$ ) for $72 \mathrm{~h}$, to reach $80-90 \%$ confluence. After this time cells were gently trypsinized and suspended in PBS. Apoptosis levels were investigated using FACS Calibur cytofluorimeter (Becton Dickinson) and Annexin-V-FLUOS Staining Kit (Roche). The test was performed on 10000 cells.

In silico analysis. hPNPase gene sequences available in the databases (accession numbers: NM_ 003109 - positions (-) 3052535-3110385 in chromosome 2, contig NT_005375 - positions (-) 3110363111407) were subjected to in silico analysis, which was performed on Genomatix server (http://www. genomatix.de) using MatInspector tool for the recognition of transcriptional elements.

\section{RESULTS}

\section{$\beta$-interferon increases the level of hPNPase mRNA}

In order to correlate the response to interferon treatment with hPNPase mRNA levels we examined different melanoma cell lines obtained from metastatic tumors that were removed surgically from patients of the Cancer Centre - Institute of Oncology in Warsaw (Poland). Five melanoma cell lines were from early passages (9-21) and four from distant passages (150-161).

Using semiquantitative RT-PCR and $\beta$-actin as an internal control we measured the hPNPase mRNA levels for the melanoma cell lines as well as for Jurkat, HEK and HeLa cells as controls. In the case of three samples, namely the line MeW151p21, Jurkat, and HeLa cells we have additionally carried out real-time PCR assays. Since the correlation between semiquantitative PCR and real-time PCR quantification in the preliminary experiments was good (not shown), we assumed that the first method is sufficient for the examination of hPNPase induction in our study: all results from melanomas are for semiquantitative RT-PCR, results for other cell lines are from real-time PCR.

The results revealed that in 8 out of 9 melanoma cell lines tested there was only a moderate increase (1.2- to 2.8-fold) in the level of hPNPase mRNA after $\beta$-interferon treatment. A similar observation was made for Jurkat and HEK cells. Only one melanoma cell line: MeW151p21 displayed more significant induction of hPNPase expression at the level of mRNA (5-fold), as compared to the untreated control. Induction was also observed in HeLa cells - 3-fold up-regulation of hPNPase mRNA in this cell line is comparable to what was observed by Leszczyniecka et al. (2003). As an additional control, we used HEK cells overexpressing hPNPase (HEKPNP), where the mRNA level was found to be 3.3fold up-regulated as compared to wt HEK cell line (Fig. 1).

\section{Protein level of hPNPase are not affected by inter- feron treatment in melanoma cell lines}

The changes in the level of a given mRNA within the cell do not always correlate with the alterations in the level of the respective protein (Scacheri et al., 2004; Le Roch et al., 2004; Schrauwen et al., 2005). Therefore, we were interested whether the increased levels of hPNPase mRNA that we observed in some melanoma cell lines and in different cells like HeLa, Jurkat, HEK and HEK-PNP result in elevated levels of protein. The amount of hPNPase protein was measured by Western blot technique employ- 


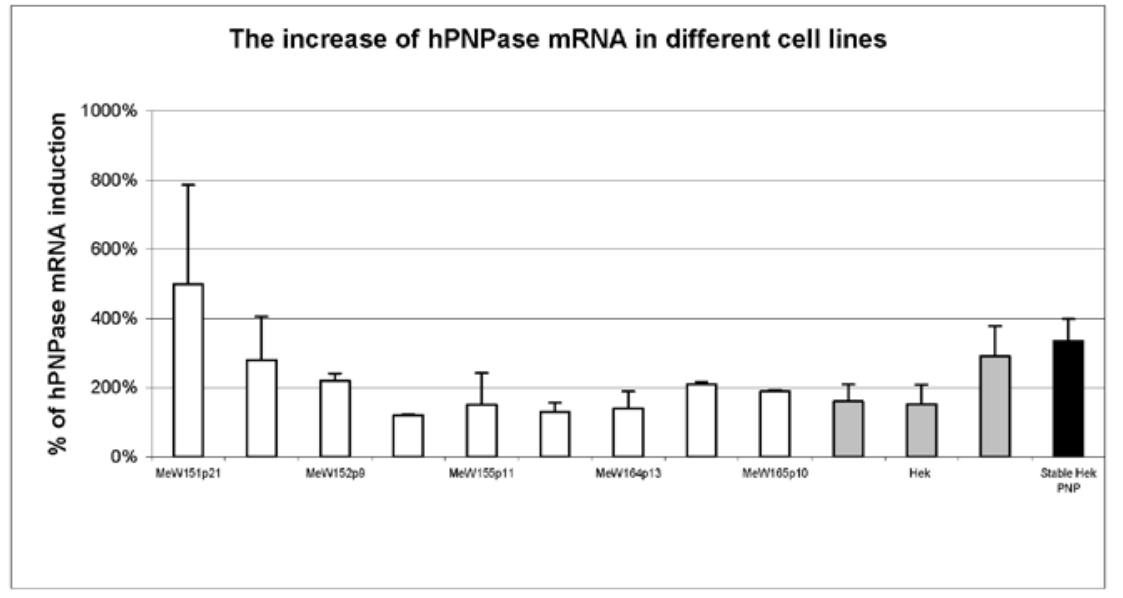

Figure 1. The hPNPase mRNA level was investigated using semiquantitative RT-PCR and/or real-time PCR at least twice for all samples.

Standardization was performed using $\beta$-actin and/or $\mathrm{B} 2 \mathrm{M}$ transcripts. Melanoma cell lines (white) and Jurkat, HEK and HeLa cells (gray) were treated with $\beta$-interferon for $24 \mathrm{~h}$. The level of hPNPase mRNA was compared with the level in untreated cells. The hPNPase mRNA level for a stable cell line overexpressing hPNPase under the control of CMV promoter (marked in black) was compared with wt HEK.

ing anti-hPNPase polyclonal antibodies (Piwowarski et al., 2003). We used exactly the same cells that had been previously used for hPNPase mRNA level assays (half of the cell volume was used for RNA and half for protein isolation). The results of the respective Western blots are presented in Fig. 2. For all melanoma cells, almost no difference between interferontreated and untreated cells was found. Conversely, we have found that in HeLa and HEK cells subjected to $\beta$-interferon treatment the expression of hPNPase at the protein level was more than twice up-regulated, in Jurkat cells the hPNPase protein level was increased by about $50 \%$, and in the stable HEK-PNP cell line there were no differences in hPNPase protein level in comparison with wt HEK cells.

Apoptosis in melanoma cell lines is not induced by interferon- $\beta$ treatment

As reported previously, interferon treatment of melanoma cell lines resulted in apoptosis (Sarkar et al., 2003). In our studies, apoptosis was investigated using annexin staining method in the cells treated with $\beta$-interferon for $72 \mathrm{~h}$. As shown in Fig. 3, no significant differences in the level of apoptotic cells were found between $\beta$-interferon treated cells and untreated melanoma cells. The cell line MeW151p21, exhibiting a highest level of hPNPase mRNA, shows

a)

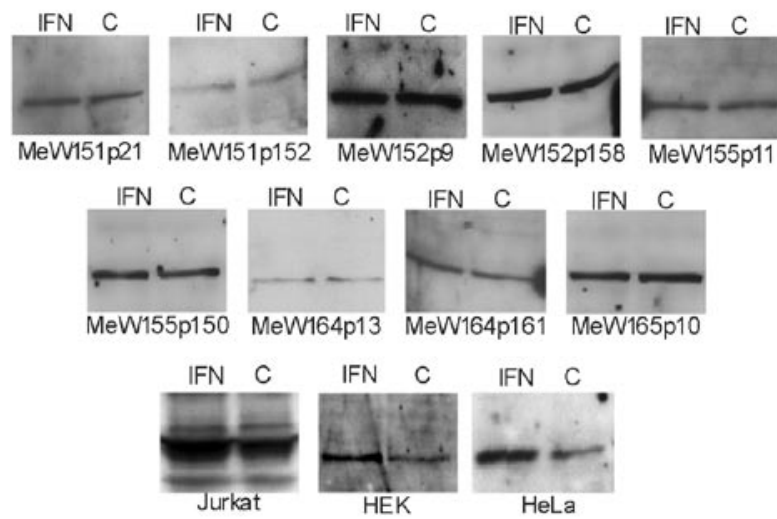

the lowest level of apoptosis in both the $\beta$-interferon treated and untreated cells. In MeW165p10 cell line the level of apoptosis was the highest but reached only about $4 \%$ both in the treated and untreated cells.

\section{Mitochondrial ND3 transcripts has shortened poly(A) tails after $\beta$-interferon treatment in Jurkat and HeLa cells}

hPNPase is involved in mRNA metabolism in human mitochondria (Tomecki et al., 2004; Nagaike et al., 2005). In HeLa cells after RNAi against hPNPase mitochondrial mRNA poly(A) tails become extended by about 20 adenines in comparison with the wild type cells (Nagaike et al., 2005). We decided to investigate the length of mitochondrial mRNAs tails after overexpression of hPNPase. Previously we estimated the length of mitochondrial oligo(A) tails as approx. $5 \mathrm{nt}$ and poly(A) tails as approx. $50 \mathrm{nt}$ (Tomecki et al., 2004). Two cell lines in which hPNPase is inducible by interferon treatment (HeLa and Jurkat) were chosen for this experiment. After $24 \mathrm{~h}$ of $\beta$-interferon treatment total RNA was isolated and separated in a $5 \%$ denaturing acrylamide gel. In both cell lines poly(A) tails of ND3 transcripts were shortened. In Jurkat cells where hPNPase is about 1.5-times up-regulated after interferon treatment we

b)

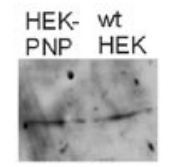

Figure 2. Western-blot analysis of hPNPase protein level.

a) interferon-treated (INF) versus untreated (C) cells (melanoma, Jurkat, HEK and HeLa) or b) HEK-PNP versus wt HEK cells. Equal protein loading was monitored by Ponceau S Red staining of the blots following semidry electrotransfer (not shown). 


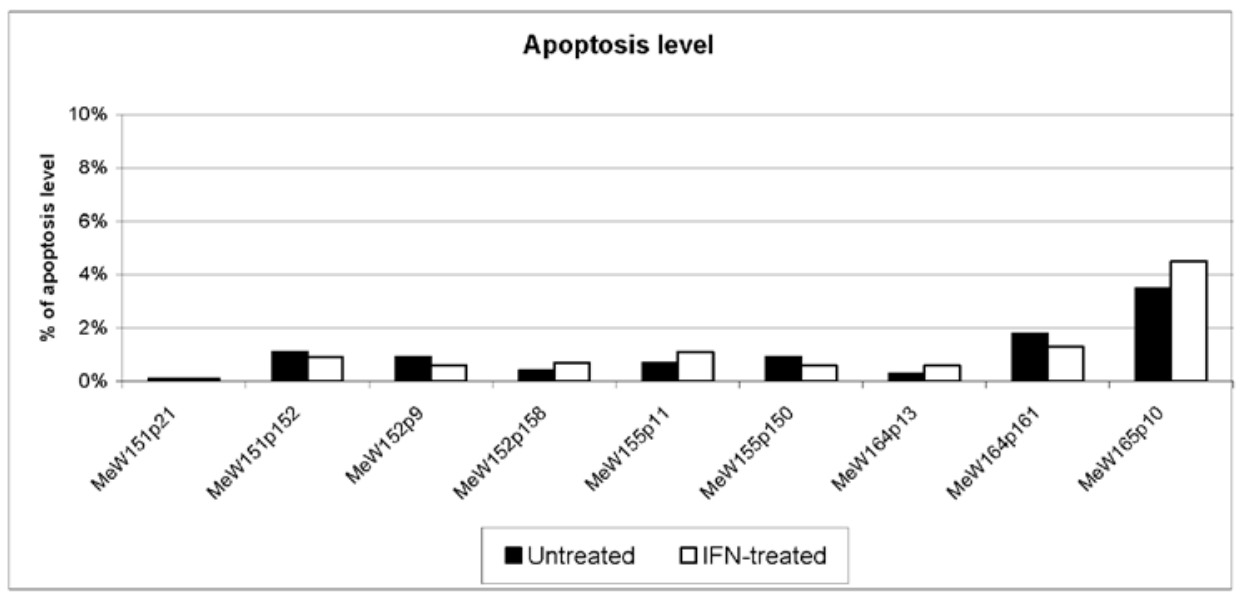

Figure 3. The level of apoptosis in melanoma cells was investigated $72 \mathrm{~h}$ after $\beta$-interferon treatment using Annexin-V-FLUOS Staining Kit and FACS analysis. Black and white bars corresponded to control and interferon-treated cells, respectively.

estimate that the poly(A) tails of ND3 transcripts were shortened by approx. $5 \mathrm{nt}$. In HeLa cells where hPNPase is about 3-times up-regulated poly(A) tails were shortened by approx. 10-15 nt (Fig. 4).

\section{In silico analysis of the hPNPase promoter region}

We performed an extensive in silico analysis of the hPNPase promoter in search for potential transcriptional elements in this region. The analysis, which was done with the use of MatInspector software led to the identification of 17 different binding sites for various transcription factors (Fig. 5 and Table 1). They can be divided into four groups: housekeeping, interferon responsive, developmental and cell cycle. Most of the motifs that were found in this study belong to the first two groups. A similar approach had been used previously for the analysis of hPNPase promoter by Leszczyniecka et al. (2003), nevertheless our results indicate the existence of many more putative regulatory sites. Among the newly discovered transcriptional elements were: a) housekeeping: ATF, CAAT, NFY, TAXCREB, NF1; b) interferon responsive: HMGIY, IRF7; c) all the developmental and cell cycle sites.

\section{DISCUSSION}

Responsiveness of patients with melanoma to interferon therapy is rather low (Worm et al., 2001; Wysocki et al., 2002; Soengas \& Lowe, 2003). Moreo-

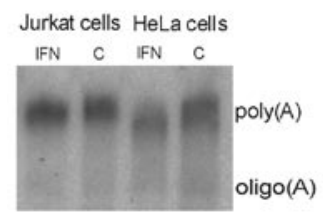

Figure 4. High-resolution Northern blot analysis of mitochondrial ND3 mRNA in control and interferon-treated Jurkat and HeLa cells.

Positions of polyadenylated (poly(A)) and oligoadenylated $($ oligo(A)) fractions are indicated. ver, studies on cell lines isolated from melanomas indicated that $\beta$-interferon induces apoptosis in only a fraction of the cell lines. On the other hand, Leszczyniecka et al. (2002) have suggested that there is a correlation between the induction of mitochondrial hPNPase by $\beta$-interferon and cell death.

Since the studies linking hPNPase induction with melanoma cell death were conducted only on the HO-1 cell line (Leszczyniecka et al., 2002), we decided to test the possible correlation using several different cell lines established from metastatic melanomas. We decided to use $\beta$-interferon as it induces hPNPase mRNA more strongly than $\alpha$-interferon (Leszczyniecka et al., 2002) and has a stronger cell growth-inhibitory effect (Borden et al., 1982; Schiller et al., 1986; Rosenblum et al., 1990; Johns et al., 1992). We investigated the induction of mitochondrial polynucleotide phosphorylase (hPNPase), both at the mRNA and protein levels, in the investigated melanoma cell lines which were subjected to $\beta$-interferon treatment under the same conditions as employed by Fisher's group. hPNPase mRNA levels in 8 cell lines were very moderately induced: ranging from 1.2 to 2.8 -fold increase. Only one melanoma cell line was much more sensitive to $\beta$-interferon induction, exhibiting a 5-fold increase of hPNPase mRNA level. HeLa, HEK and Jurkat cell lines were found to differ in their response to $\beta$-interferon: we observed a relatively strong - about 3-fold induction in HeLa and HEK cells, while low induction was found in the case of Jurkat cells.

The important observation is that the changes in hPNPase mRNA levels did not correlate with the levels of the respective protein. Although the induction of hPNPase mRNA levels varied from 1.2- to 5-fold, depending on the cell line, in all tested melanoma cell lines the level of hPNPase protein remained unchanged after interferon treatment. Also in HEK-PNP cell line the over 3-fold overexpression of hPNPase at the mRNA level did not affect the protein level. In contrast, in HeLa, HEK and Jurkat cells $\beta$-interferon treatment led to the 
Table 1. The function of the putative transcriptional factors that might be involved in the regulation of hPNPase expression

\begin{tabular}{|c|c|c|}
\hline & Factor's name (family) & Function \\
\hline 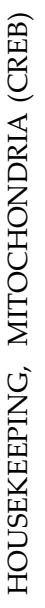 & $\begin{array}{l}\text { ATF(CREB) } \\
\text { CAAT(PCAT) } \\
\text { E4BP4(CREB) } \\
\text { GC(SP1F)* } \\
\text { NFY(ECAT) } \\
\text { TAXCREB(CREB) }\end{array}$ & $\begin{array}{l}\text { Activating transcription factor (Rooney et al., 1990). } \\
\text { Cellular and viral CAAT-box. Transcriptional factor connected with CAAT-box } \\
\text { (Benoist et al., 1980); possible interaction with NFY. } \\
\text { Transcriptional repressor (Cowell et al., 1992); interaction with OCT1P. } \\
\text { Transcriptional factor connected with GC-islands and housekeeping gene ex- } \\
\text { pression (Kadonaga et al., 1986). } \\
\text { Nuclear factor Y (Y-box binding factor), transcriptional factor connected with } \\
\text { CAAT-box (Dorn et al., 1987); possible interaction with CAAT0.1. } \\
\text { cAMP response element binding protein, connected with signal transduction by } \\
\text { cAMP (Paca-Uccaralertkun et al., 1994). } \\
\text { Nuclear factor } 1 \text { is a family of activators and sometimes repressors of transcrip- } \\
\text { tion. NF1 have been implicated in tissue-specific expression of various genes } \\
\text { (Bedford et al., 1998). }\end{array}$ \\
\hline 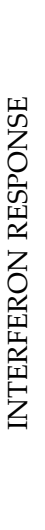 & $\begin{array}{l}\text { HMGIY(SORY) } \\
\text { IRF1(IRFF)* } \\
\text { IRF7 (IRFF) } \\
\text { ISRE (IRFF)* } \\
\text { STAT1 (STAT)* }\end{array}$ & $\begin{array}{l}\text { High-mobility-group protein I (Y). Enhancer of different transcriptional factors, } \\
\text { for example IRF1. Its interaction was discovered in many cytokine promoters } \\
\text { like IFN- } \beta \text {. This factor is necessary for viral induction of IFN- } \beta \text { gene (Yie et al., } \\
\text { 1997); possible interaction with transcriptional factors from POU (OCT) group. } \\
\text { Interferon regulatory factor 1. Interferon-induced factor involved in gene ex- } \\
\text { pression during interferon response (Harada et al., 1989). } \\
\text { Interferon regulatory factor } 7 \text {. Interferon-induced factor involved in gene ex- } \\
\text { pression during interferon response (Zhang \& Pagano, 1997). } \\
\text { Interferon-stimulated response element. IRF1 and ISGF3 binding site connected } \\
\text { with interferon response (Levy et al., 1988). } \\
\text { Signal transducers and activators of transcription. Ligand-activated transcrip- } \\
\text { tional factor and signal transducer involved in apoptosis (Horvath et al., 1995). }\end{array}$ \\
\hline 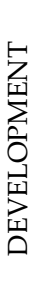 & $\begin{array}{l}\text { GLI1(GLIF) } \\
\text { OCT1P(OCTP) } \\
\text { OCT1(OCT) }\end{array}$ & $\begin{array}{l}\text { Transcriptional regulator involved in cell growth and tissues development, con- } \\
\text { nected with human hedgehog homolog proteins (Pearse et al., 1999). } \\
\text { Octamer binding factor 1. Transcriptional factor involved in development } \\
\text { and homeotic gene expression regulation (Verrijzer et al., 1992); interacting with } \\
\text { E4BP4, and possibly with HMGIY.01 } \\
\text { Oct1 functions as an activator of a wide range of genes required for development, dif- } \\
\text { ferentiation and homeostasis (Reece-Hoyes et al., 2005). }\end{array}$ \\
\hline 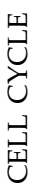 & FAST1(FAST) & $\begin{array}{l}\text { Transcriptional repressor responsible for gene silencing during } G_{1} \text { to } S \text { phase transition } \\
(\text { Wu et al., 2001). } \\
\text { Activin signal transducer. Gene expression activator in the presence of TGF- } \beta \\
\text { (Zhou et al., 1998). }\end{array}$ \\
\hline
\end{tabular}

*Previously described in (Leszczyniecka et al., 2003).

increase in both mRNA and protein levels. Thus, our data confirm the observations of Leszczyniecka et al. (2002), that $\beta$-interferon treatment can increase hPNPase mRNA levels in human melanoma cells. We showed, however, that the relative increase of the mRNA level varied greatly among melanoma cell lines and that the up-regulation of hPNPase mRNA did not result in the increase of the protein level.
We measured apoptosis in all melanoma cell lines treated with $\beta$-interferon. The level of apoptosis was very low (around $1 \%$ in 8 cases) and no significant correlation between treated and untreated cells could be observed, as well as between melanoma cell lines in the early and late stage of growth in vitro. In one cell line (MeW165p10) the level of apoptosis reached $4 \%$ but the difference between treated and untreated cells was also negligible. Thus, poor 


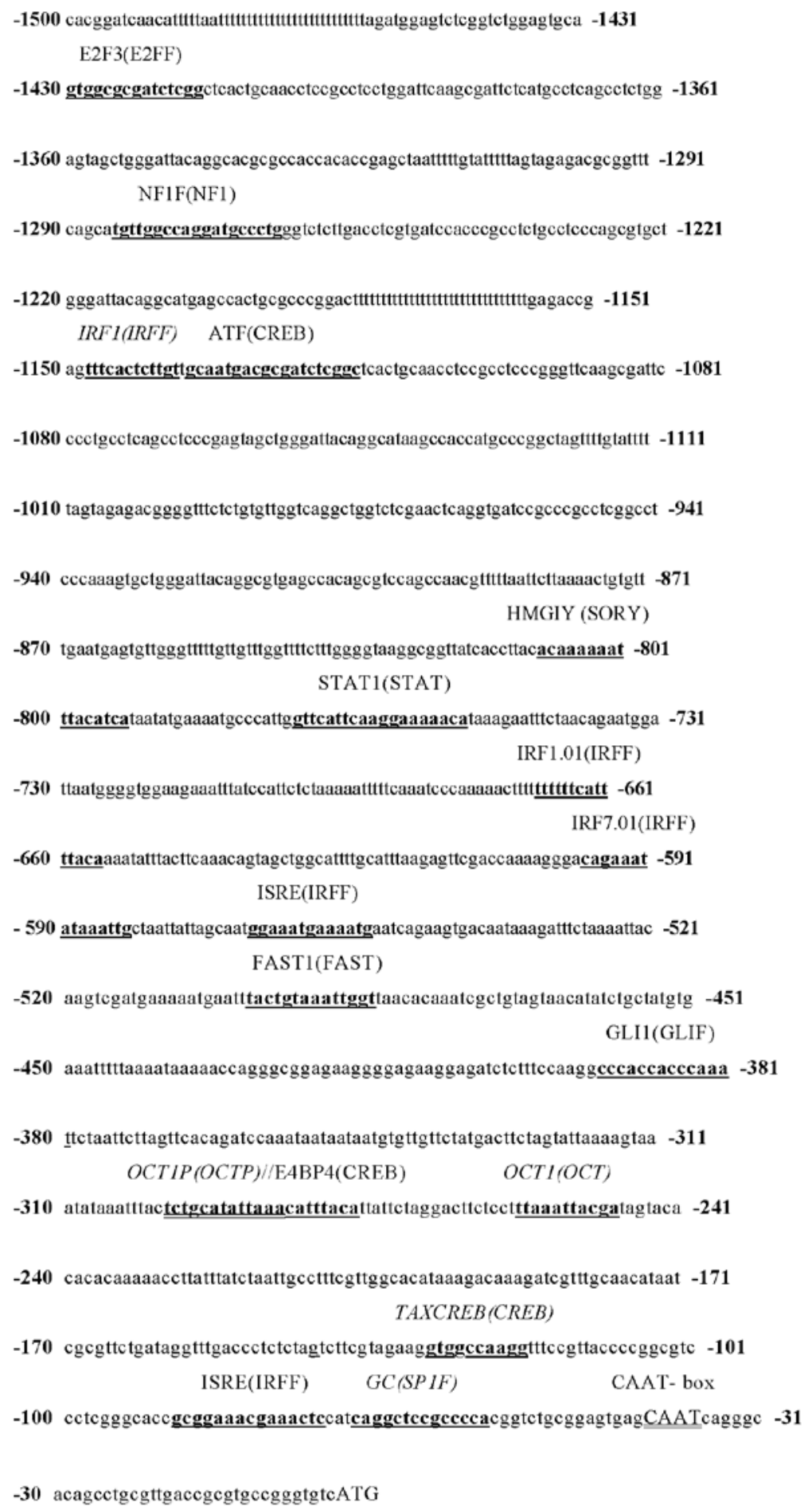

response of hPNPase protein to interferon treatment correlates with the lack of apoptosis.

We have studied the hPNPase promoter using an in silico analysis and we have found numerous sites which have not been shown in the previously published data. The hPNPase promoter differs significantly from other promoters of genes coding proteins involved in mitochondrial RNA metabolism. Two examples of such genes: hSUV3 and hmtPAP encoding RNA/DNA helicase and poly(A) polymerase, respec- tively, contain a very limited set of regulatory protein binding sites, characteristic for housekeeping genes (Minczuk et al., 2005; our unpublished data). In contrast to that, the hPNPase promoter displays a wide variety of binding sites. Among them, of special interest are interferon responsive elements and cell cycle-related elements. Such a complex structure of the hPNPase promoter may indicate the important function of polynucleotide phosphorylase in controlling cell cycle events. The experiments of Leszczyniecka et 
al. (2002) showing the significant up-regulation of $\mathrm{hP}$ NPase mRNA in progeroid fibroblasts entering senescent status is a further proof of the importance of $\mathrm{hP}$ NPase regulation in cell cycle events. In spite of these clues, the molecular mechanism of hPNPase function remains obscure.

The only phenotype effect of up-regulation of hPNPase was found by us in HeLa and Jurkat cells. After interferon induction of hPNPase the mitochondrial ND3 poly(A) tails were shortened. This effect is opposite to the results of hPNPase silencing (Nagaike et al., 2005; and our unpublished data), where knock-down of hPNPase expression resulted in the increased length of mitochondrial poly(A) tails.

There is a lot of evidence that after interferon treatment the level of mitochondrial RNA is decreased (Shan et al., 1990; Inagaki et al., 1997; Le Roy et al., 2001). The mechanism of this phenomenon is not clear yet but few hypotheses have been proposed. One of them suggests a decrease of mitochondrial transcription caused by reduction of mitochondrial transcription factor (Inagaki et al., 1997). The second one is based on the shortened half-life of RNA caused by mitochondrial RNase L which inhibitor is reduced by interferon (Le Roy et al., 2001). Our results indicate a third possibility that the decrease of mitochondrial RNA level could be caused by shortening of their poly(A) tails by hPNPase.

\section{Acknowledgements}

We are indebted to Professor E. Bartnik for critical reading of the manuscript. This work was supported by the State Committee for Scientific Research (KBN) grant No. PBZ-KBN-091/P05/2003/40. The authors are members of an EU-funded MitEuro Network. R. T. is the recipient of a scholarship from the Postgraduate School of Molecular Medicine affiliated with the Medical University of Warsaw.

\section{REFERENCES}

Bedford FK, Julius D, Ingraham HA (1998) Neuronal expression of the 5HT3 serotonin receptor gene requires nuclear factor 1 complexes. J Neurosci 18: 6186-6194.

Benoist C, O'Hare K, Breathnach R, Chambon P (1980) The ovalbumin gene-sequence of putative control regions. Nucleic Acids Res 8: 127-142.

Borden EC, Hogan TF, Voelkel JG (1982) Comparative antiproliferative activity in vitro of natural interferons alpha and beta for diploid and transformed human cells. Cancer Res 42: 4948-4953.

Chawla-Sarkar M, Leaman DW, Borden EC (2001) Preferential induction of apoptosis by interferon (IFN)-beta compared with IFN-alpha2: correlation with TRAIL/ Apo2L induction in melanoma cell lines. Clin Cancer Res 6: 1821-1831.
Cowell IG, Skinner A, Hurst HC (1992) Transcriptional repression by a novel member of the bZIP family of transcription factors. Mol Cell Biol 12: 3070-3077.

Dorn A, Bollekens J, Staub A, Benoist C, Mathis D (1987) A multiplicity of CCAAT box-binding proteins. Cell 50: 863-872.

Harada H, Fujita T, Miyamoto M, Kimura Y, Maruyama M, Furia A, Miyata T, Taniguchi T (1989) Structurally similar but functionally distinct factors, IRF-1 and IRF2 , bind to the same regulatory elements of IFN and IFN-inducible genes. Cell 58: 729-739.

Horvath CM, Wen Z, Darnell JE Jr (1995) A STAT protein domain that determines DNA sequence recognition suggests a novel DNA-binding domain. Genes Dev 9: 984-994.

Inagaki H, Matsushima Y, Ohshima M, Kitagawa Y (1997) Interferons suppress mitochondrial gene transcription by depleting mitochondrial transcription factor A (mtTFA). J Interferon Cytokine Res 17: 263-269.

Johns TG, Mackay IR, Callister KA, Hertzog PJ, Devenish RJ, Linnane AW (1992) Antiproliferative potencies of interferons on melanoma cell lines and xenografts: higher efficacy of interferon beta. J Natl Cancer Inst 84: 1185-1190.

Kadonaga JT, Jones KA, Tjian R (1986) Promoter-specific activation of RNA polymerase II transcription by Sp1. Trends Biochem Sci 11: 20-23.

Kortsaris A, Taylor-Papadimitriou J, Georgatsos JG (1976) Interferon inhibition of protein synthesis by isolated mitochondria. Biochem Biophys Res Commun 68: 1317-1322.

Kulik J, Nowecki ZI, Rutkowski P, Ruka W, Rochowska M, Skurzak H, Siedlecki JA (2001) Detection of circulating melanoma cells in peripheral blood by a two-marker RT-PCR assay. Melanoma Res 11: 65-73.

Le Roch KG, Johnson JR, Florens L, Zhou Y, Santrosyan A, Grainger M, Yan SF, Williamson KC, Holder AA, Carucci DJ, Yates JR 3rd, Winzeler EA (2004) Global analysis of transcript and protein levels across the Plasmodium falciparum life cycle. Genome Res 14: 2308-2318.

Le Roy F, Bisbal C, Silhol M, Martinand C, Lebleu B, Salehzada T (2001) The 2-5A/RNase L/RNase L inhibitor (RLI) [correction of (RNI)] pathway regulates mitochondrial mRNAs stability in interferon alpha-treated H9 cells. J Biol Chem 276: 48473-48482.

Leaman DW, Chawla-Sarkar M, Vyas K, Reheman M, Tamai K, Toji S, Borden EC (2002) Identification of X-linked inhibitor of apoptosis-associated factor-1 as an interferon-stimulated gene that augments TRAIL Apo2L-induced apoptosis. J Biol Chem 32: 28504-28511.

Leszczyniecka M, Kang DC, Sarkar D, Su ZZ, Holmes M, Valerie K, Fisher PB (2002) Identification and cloning of human polynucleotide phosphorylase, hPNPase old-35, in the context of terminal differentiation and cellular senescence. Proc Natl Acad Sci USA 26: 16636-16641.

Leszczyniecka M, Su ZZ, Kang DC, Sarkar D, Fisher PB (2003) Expression regulation and genomic organization of human polynucleotide phosphorylase, hPNPase(old$35)$, a type I interferon inducible early response gene. Gene 316: 143-156.

Levy DE, Kessler DS, Pine R, Reich N, Darnell JE Jr (1988) Interferon-induced nuclear factors that bind a shared promoter element correlate with positive and negative transcriptional control. Genes Dev 2: 383-393.

Matarrese P, Di Biase L, Santodonato L, Straface E, Mecchia M, Ascione B, Parmiani G, Belardelli F, Ferrantini M, Malorni W (2002) Type I interferon gene transfer sensitizes melanoma cells to apoptosis via a target activity on mitochondrial function. Am J Pathol 160: 1507-1520. 
Minczuk M, Lilpop J, Boros J, Stepien PP (2005) The 5' region of the human hSUV3 gene encoding mitochondrial DNA and RNA helicase: promoter characterization and alternative pre-mRNA splicing. Biochim Biophys Acta 1729: 81-87.

Nagaike T, Suzuki T, Katoh T, Ueda T (2005) Human mitochondrial mRNAs are stabilized with polyadenylation regulated by mitochondria-specific poly(A) polymerase and polynucleotide phosphorylase. J Biol Chem 20: 19721-19727.

Paca-Uccaralertkun S, Zhao LJ, Adya N, Cross JV, Cullen BR, Boros IM, Giam CZ (1994) In vitro selection of DNA elements highly responsive to the human Tcell lymphotropic virus type I transcriptional activator, Tax. Mol Cell Biol 14: 456-462.

Pearse RV 2nd, Collier LS, Scott MP, Tabin CJ (1999) Vertebrate homologs of Drosophila suppressor of fused interact with the gli family of transcriptional regulators. Dev Biol 212: 323-336.

Piwowarski J, Grzechnik P, Dziembowski A, Dmochowska A, Minczuk M, Stepien PP (2003) Human polynucleotide phosphorylase, hPNPase, is localized in mitochondria. J Mol Biol 5: 853-857.

Reece-Hoyes JS, Keenan ID, Pownall ME, Isaacs HV (2005) A consensus Oct1 binding site is required for the activity of the Xenopus Cdx4 promoter. Dev Biol 282: 509-523.

Rooney RJ, Raychaudhuri P, Nevins JR (1990) E4F and ATF, two transcription factors that recognize the same site, can be distinguished both physically and functionally: a role for E4F in E1A trans activation. Mol Cell Biol 10: 5138-5149.

Rosenblum MG, Yung WK, Kelleher PJ, Ruzicka F, Steck PA, Borden EC (1990) Growth inhibitory effects of interferon-beta but not interferon-alpha on human glioma cells: correlation of receptor binding, 2',5'-oligoadenylate synthetase and protein kinase activity. J Interferon Res 10: 141-151.

Sarkar D, Leszczyniecka M, Kang DC, Lebedeva IV, Valerie K, Dhar S, Pandita TK, Fisher PB (2003) Down-regulation of Myc as a potential target for growth arrest induced by human polynucleotide phosphorylase (hPNPaseold-35) in human melanoma cells. J Biol Chem 27: 24542-24551.

Sarkar D, Lebedeva IV, Emdad L, Kang DC, Baldwin AS Jr, Fisher PB (2004) Human polynucleotide phosphorylase ( $h P N P a s e o l d-35)$ : a potential link between aging and inflammation. Cancer Res 20: 7473-7478.

Scacheri PC, Rozenblatt-Rosen O, Caplen NJ, Wolfsberg TG, Umayam L, Lee JC, Hughes CM, Shanmugam KS, Bhattacharjee A, Meyerson M, Collins FS (2004) Short interfering RNAs can induce unexpected and divergent changes in the levels of untargeted proteins in mammalian cells. Proc Natl Acad Sci USA 101: 1892-1897.

Schiller JH, Willson JK, Bittner G, Wolberg WH, Hawkins MJ, Borden EC (1986) Antiproliferative effects of interferons on human melanoma cells in the human tumor colony-forming assay. J Interferon Res 6: 615-265.

Schrauwen P, Russell AP, Moonen-Kornips E, Boon N, Hesselink MK (2005) Effect of 2 weeks of endurance training on uncoupling protein 3 content in untrained human subjects. Acta Physiol Scand 183: 273-280.

Shan B, Vazquez E, Lewis JA (1990) Interferon selectively inhibits the expression of mitochondrial genes: a novel pathway for interferon-mediated responses. EMBO J 9: 4307-4314.

Soengas MS, Lowe SW (2003) Apoptosis and melanoma chemoresistance. Oncogene 22: 3138-3151.

Tomecki R, Dmochowska A, Gewartowski K, Dziembowski A, Stepien PP (2004) Identification of a novel human nuclear-encoded mitochondrial poly(A) polymerase. Nucleic Acids Res 20: 6001-6014.

Vandesompele J, De Preter K, Pattyn F, Poppe B, Van Roy N, De Paepe A, Speleman F (2002) Accurate normalization of real-time quantitative RT-PCR data by geometric averaging of multiple internal control genes. Genome Biol 3: research 00341-00411.

Verrijzer CP, Alkema MJ, van Weperen WW, Van Leeuwen HC, Strating MJ, van der Vliet PC (1992) The DNA binding specificity of the bipartite POU domain and its subdomains. EMBO J 11: 4993-5003.

Worm M, Schadendorf D, Czarnetzki BM (1993) Responsiveness to interferon treatment of human melanoma cells correlates to immunophenotype. Melanoma Res 3: 29-33.

Wu L, Timmers C, Maiti B, Saavedra HI, Sang L, Chong GT (2001) The E2F1-3 transcription factors are essential for cellular proliferation. Nature 414: 457-462.

Wysocki PJ, Karczewska A, Mackiewicz A (2002) Gene modified tumor vaccines in therapy of malignant melanoma. Otolaryngol Pol 56: 147-153.

Yie J, Liang S, Merika M, Thanos D (1997) Intra- and intermolecular cooperative binding of high-mobility-group protein $\mathrm{I}(\mathrm{Y})$ to the $\beta$-interferon promoter. Mol Cell Biol 17: 3649-3662.

Zhang L, Pagano JS (1997) IRF-7, a new interferon regulatory factor associated with Epstein-Barr virus latency. Mol Cell Biol 17: 5748-5757.

Zhou S, Zawel L, Lengauer C, Kinzler KW, Vogelstein B (1998) Characterization of human FAST-1, a TGF beta and activin signal transducer. Mol Cell 2: 121-127. 